\title{
https://doi.org/10.30853/manuscript.2020.4.31
}

\section{Чжан Тяньцзяо}

Влияние Н. М. Сокольского на ранний китайский балет

В статье изучается влияние на ранний китайский балет Н. М. Сокольского, который создал балетную труппу "Русский балет в Шанхае", тем самым способствуя распространению классического танца во всем Китае. Также рассматривается целая плеяда талантливых китайских артистов - учеников Н. М. Сокольского, внесших в дальнейшем большой вклад в развитие национальной танцевальной культуры. Отмечается, что инициатива Сокольского изменила эстетическое восприятие шанхайской публики, ускорила распространение среди публики и влияние на профессиональную среду западной танцевальной культуры в Китае. На примерах воспоминаний учеников Сокольского прослеживаются принципы его педагогической работы в стенах Центральной академии драмы (первой высшей академии театрального образования в КНР). Автор приходит к выводам относительно влияния работы Сокольского на ранний китайский балет.

Адрес статьи: www.gramota.net/materials/9/2020/4/31.html

\section{Источник}

\section{Манускрипт}

Тамбов: Грамота, 2020. Том 13. Выпуск 4. С. 149-155. ISSN 2618-9690.

Адрес журнала: www.gramota.net/editions/9.html

Содержание данного номера журнала: www.gramota.net/materials/9/2020/4/

\section{() Издательство "Грамота"}

Информация о возможности публикации статей в журнале размещена на Интернет сайте издательства: www.gramota.net

Вопросы, связанные с публикациями научных материалов, редакция просит направлять на адрес: hist@gramota.net 
сочетались бы с воспитательной работой внутри коллектива. Пьесы, включаемые в репертуар коллектива, по художественным достоинствам должны быть не ниже пьес профессионального театра и должны отвечать специфическим требованиям и уровню мастерства исполнителей-любителей [4].

Репертуарная политика формируется, как известно, во взаимодействии театра и аудитории и тем самым отражает многообразие социальных связей театрального процесса в целом. Данное исследование показывает целостную картину театральной жизни Белгородской области и определенную взаимодополняемость факторов, влияющих на формирование театрального репертуара любительских коллективов и социального контекста театральной жизни региона.

\title{
Список источников
}

1. Куц С. Ф., Бокий-Мощенских В. А. Выбор репертуара в детском театральном коллективе // Учёные записки (Алтайская государственная академия культуры и искусств). 2018. № 1 (15). С. 81-84.

2. Литовский О. Так было. М.: Искусство, 1958. 137 с.

3. Сазонова В. А. Театральная педагогика Ю. А. Завадского [Электронный ресурс]: учебное пособие. Изд-е 3-е, доп. СПб.: Планета музыки, 2019. 176 c. URL: https://e.lanbook.com/book/113980 (дата обращения: 14.03.2020).

4. Сапегин Б. В. Режиссер самодеятельного театрального коллектива: учебное пособие для студентов отделения режиссуры драмы института культуры. Л.: Искусство, 1986. 146 с.

5. Театр и публика: опыт социологического исследования 1960-1970-х годов / отв. ред. В. Н. Дмитриевский. М.: Государственный институт искусствознания «Реабилитация», 2013. 400 с.

6. Товстоногов Г. А. Парадокс о зрителе // Литературная газета. 1973. 23 мая.

7. Хренов Н. А. Театр как социологический феномен // Алексеев А. Н., Дмитриевский В. Н. Театральный репертуар как объект социологического исследования. СПб.: Алетейя, 2009. С. 314-327.

\section{Repertoire Policy of Modern Amateur Theatre Groups: Attempt of Sociological Research}

\author{
Rashina Tat'yana Olegovna \\ Mikhailova Ol'ga Aleksandrovna \\ Plekhova Veronika Vladimirovna \\ Belgorod State University of Arts and Culture \\ 27luna@rambler.ru; olga11846@mail.ru; veronika-nika76@mail.ru
}

\begin{abstract}
The article examines the problem of choosing theatre repertoire, analyses the basic principles of its formation in amateur and professional theatre groups. A comparative analysis is conducted. Special attention is paid to repertoire policy of Belgorod region theatres: monitoring of the stage directors' preferences was implemented with a view to identify their motives for choosing plays of a certain domestic or foreign author, of a particular genre, time period. The factors influencing the choice of amateur theatres repertoire are determined and an integral picture of theatrical life in Belgorod region is presented.
\end{abstract}

Key words and phrases: repertoire; repertoire policy; factors influencing the choice of amateur theatres' repertoire; comparative analysis; modern sociocultural situation.

В статье изучается влияние на ранний китайский балет Н. М. Сокольского, который создал балетную труппу «Русский балет в Шанхае», тем самым способствуя распространению классического таниа во всем Китае. Также рассматривается целая плеяда талантливых китайских артистов - учеников Н. М. Сокольского, внесших в дальнейшем большой вклад в развитие национальной танщевальной культуры. Отмечается, что инициатива Сокольского изменила эстетическое восприятие шанхайской публики, ускорила распространение среди публики и влияние на профессиональную среду западной танцевальной культуры в Китае. На примерах воспоминаний учеников Сокольского прослеживаются принципь его педагогической работы в стенах Центральной академии драмы (первой высшей академии театрального образования в КНР). Автор приходит к выводам относительно влияния работь Сокольского на ранний китайский балет.

Ключевые слова и фразы: балет; Китай; Н. М. Сокольский; «Русский балет в Шанхае»; учебный курс по танцевальному движению; зарубежное влияние на китайский балет.

\author{
Чжан Тяньцзяо \\ Российский институт театрального искусства - ГИТИС, г. Москва \\ Tianj.zhang@yandex.ru
}

\section{Влияние Н. М. Сокольского на ранний китайский балет}

Распространение русской хореографической школы в XX веке стало основой для возникновения национальных балетных школ по всему миру. Каждый раз история её восприятия какой-либо национальной культурой 
была самобытна и связана с разнообразными влияниями и деятельностью конкретных педагогов, артистов, балетмейстеров. Целью данной работы является анализ влияния Н. М. Сокольского на ранний, ещё только формирующийся китайский балет. В связи с этим формируются задачи - рассмотреть особенности его разнообразной деятельности в Китае (сначала как танцовщика и организатора труппы, после - как педагога, очень много сделавшего для подготовки уже национальных кадров для балета) и оценить его значение для развития китайского балета. Научную новизну статьи обуславливает тот факт, что деятельность Н. М. Сокольского в Китае ещё не была изучена.

В 1917 году в России произошла Великая Октябрьская социалистическая революция. Изменение общественного строя в советской России и последовавшая гражданская война, следствием которой стало ухудшение экономического положения страны, поставили перед артистами некогда великолепного русского балета дилемму - оставаться подданными нового государства или эмигрировать в другие страны. В первые годы Советской власти очень часто ставился вопрос, нужен ли балет простому народу России, ведь балет всегда считался искусством, предназначенным для высших слоев общества. Важное значение классического балета для народа поняли несколько позже, благодаря просветительской работе и отчаянной борьбе за сохранение искусства прошлых веков наркома просвещения А. В. Луначарского.

В то же время благодаря Китайско-Восточной железной дороге и открытию еженедельных морских перевозок из Владивостока в Шанхай, осуществляемых компанией «Добровольный флот», увеличилось количество торговых операций между Россией и Китаем, а потому связь России с Харбином, Шанхаем и другими городами Китая дополнительно укрепилась и стала постоянной.

Некоторые талантливые хореографы, работающие в области образования, исполнительского мастерства, а также народные танцевальные коллективы были вынуждены покинуть Россию, переехать в Харбин, Шанхай и другие города Китая для сохранения своих танцевальных трупп и ведущих артистов. Среди них были: А. И. Гравцев, В. В. Кларин, Н. А. Князев, Е. Преображенская, Т. П. Светланова, Ф. Ф. Шевлюгин, Э. И. Элиров и другие [11, с. 403]. Также в Китай эмигрировал артист и режиссер балета Н. М. Сокольский.

Николай Михайлович Сокольский (1886-1971) - солист Мариинского театра, ученик Н. Г. Легата и Э. Чеккетти. С труппой С. П. Дягилева он гастролировал по городам Европы, а с 1927 года жил в Харбине [7, с. 49]. В 1929 году он переехал в Шанхай, где основал труппу «Русский балет» Сокольского, а в 1934 году - труппу «Русский балет в Шанхае» (Илл. 1).

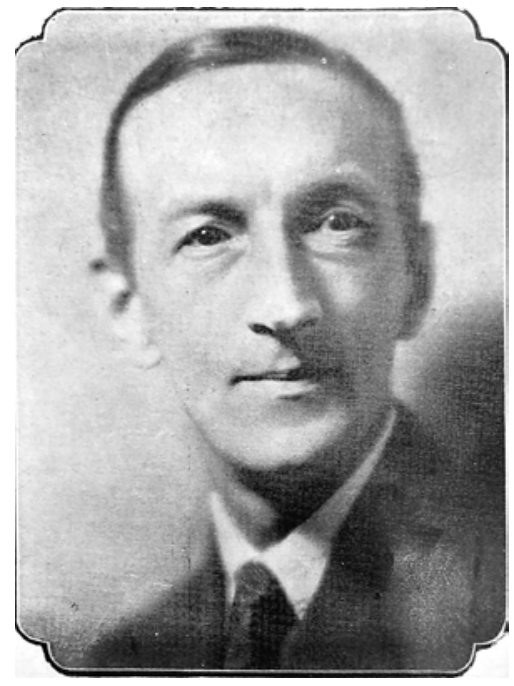

Иллюстрация 1. Н. М. Сокольский (илл. из книги «Русские в Шанхае») [2]

Там же - в Шанхае - Сокольский создал собственную школу танцев, из стен которой вышли многие впоследствии прославившиеся деятели китайского балета, в том числе: Ху Жунжун (будущий директор Шанхайской танцевальной школы) и Е Нин (будущий директор исследовательского бюро Пекинской академии танца). В 1951 году Сокольский преподавал классический балет и историю балета в Центральной академии драмы. Позже, уже вернувшись в Россию в 1953 году и поселившись в 1959 году в Великих Луках, он работал хореографом в доме культуры имени Ленина и преподавал танец в китайском стиле. А для постановок на сцене этого дома культуры он использовал некоторые костюмы и декорации, привезённые из Китая.

Попытка осмыслить влияние Сокольского на ранний китайский балет первой половины XX века (как на собственно хореографию балетного спектакля, так и на методику преподавания классического танца в Китае) была в своё время предпринята в единственной статье [1], тогда как для развития балета в Китае он сделал чрезвычайно много.

\section{Хореографическая деятельность Н. М. Сокольского в Китае}

С 1927 года, обозначившего начало короткого присутствия Сокольского в Харбине, он участвовал в ранних постановках балетных спектаклей, исполнял сольные и дуэтные танцы, составлявшие концертные 
программы вместе с операми, опереттами и инструментальными номерами, которые также звучали на харбинской сцене. Но после японского вторжения в три провинции на северо-востоке Китая он переехал в Шанхай.

В конце 1920-х годов балет как вид искусства только начал зарождаться в Китае. В отличие от бальных танцев, местным жителям он знаком не был. Статьи о выступлениях труппы Сокольского «Русский балет», появлявшиеся в газетах и буклетах, лишь изредка привлекали внимание китайцев. На шанхайской сцене в то время танцевали многие исполнители $[2 ; 11 ; 12]$. Это хореографическое трио «Олимпик» (В. Н. Волкова, Г. П. Гончаров и С. Г. Торопов), танцевальные дуэты (О. П. Манжелей и Б. А. Серов, А. С. Роговская и Ф.Ф. Шевлюгин,

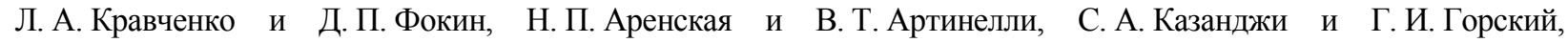
Л. К. Никитина и Н. А. Светланов, К. и А. Сахаровы); танцовщики-солисты (А. Г. Недлер, К. П. Маклецова, О.Н.Воробьева, В. И. Кутайсов, Л. Ельник, Н. В. Недзвецкая, А. Н. Андреева, Е. В. Бобынина, Н. В. Кожевникова), а также артисты, активно участвовавшие в постановках оперных спектаклей и русской оперетты (3. А. Битнер, Н. Н. Маковская, М. Н. Новацкая и др.) (Илл. 2).

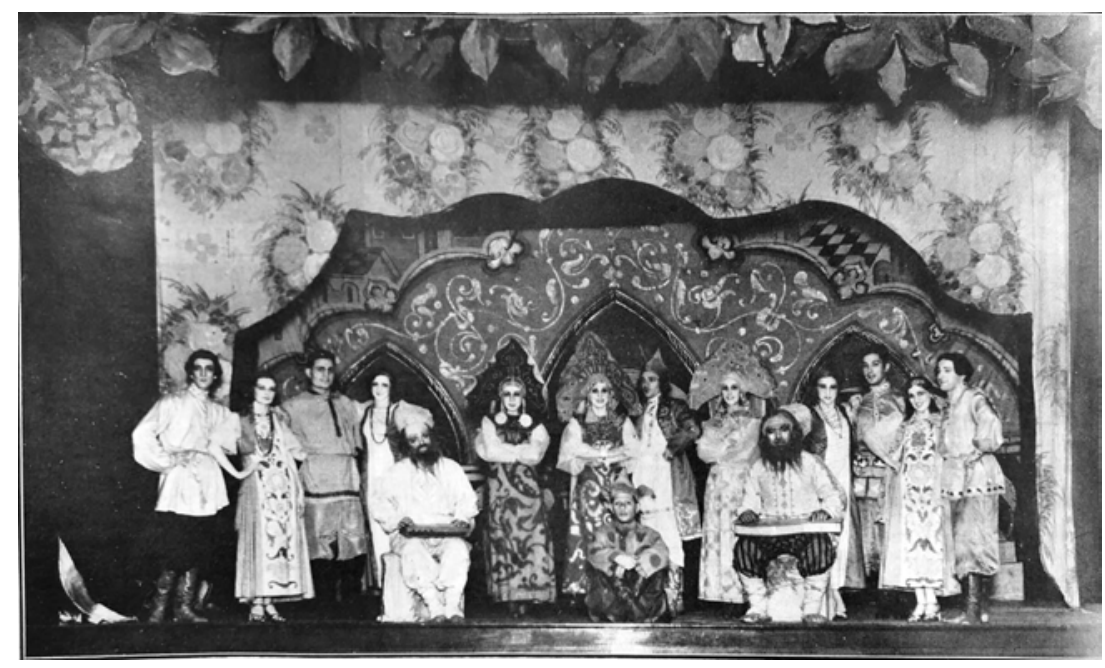

Иллюстрация 2. «Русский терем» - постановка Н. М. Сокольского (первый слева-Сокольский). Шанхай (илл. из книги «Русские в Шанхае») [2]

Балетные постановки оказали глубокое влияние на зрителей. Повышался интерес публики к «экзотическим» танцам (такой «экзотикой» и был балет), а вместе с интересом рос и «спрос» на балетные спектакли. Однако сольное или дуэтное выступление логичным образом не могло полностью удовлетворить интерес к масштабным постановкам, что и способствовало в результате официальному учреждению труппы «Русский балет в Шанхае».

13 ноября 1934 года Сокольский основал “Le Ballet Russe” (его официальное название - «Русский балет в Шанхае»), также известный как “ADC” (Amateur Dramatic Club of Shanghai). Это была вокальная и танцевальная труппа, ставшая и эксклюзивным арендатором театра «Лайсеум», и основным исполнителем на его сцене [9, с. 656]. В то время «Лайсеум» был одним из лучших театров Шанхая, а информация о работавшей в нем труппе и спектаклях публиковалась в основном в русскоязычной газете «Шанхайская заря» и китайскоязычной газете «Шанбао».

Хореографами этой труппы были Ф. Ф. Шевлюгин, Е. В. Бобынина, Н. Недвезицкая, А. Астровская, И. Постоковская, Н. Чесменская, Е. А. Преображенская, Е. Баранова, Н. Кожевникова, Л. Леонидов и др. [6, с. 10]. А в спектаклях часто участвовали известные (в основном русские) танцовщики - в труппе было много других первоклассных артистов балета с богатым опытом выступлений как в Китае, так и за рубежом.

Дирижерами оркестра шанхайского «Русского балета» были А. Ю. Слуцкий и А. Г. Бершадский, художниками-постановщиками - М. Ф. Домрачев и М. Айн [9, с. 657-658].

Артисты в основном выступали в постановках больших балетов, таких как «Четвертая симфония», «Лебединое озеро», «Павильон Армиды», «Шехерезада», «Царь-девица» («Конёк-Горбунок»), «Собор Парижской Богоматери» («Эсмеральда»), «Золотой петушок», «Франческа да Римини», «Спящая красавица», «Корсар», «Дон Кихот» [10, с. 120]. Помимо собственных выступлений, труппа много сотрудничала с другими художественными коллективами, например, с Шанхайским симфоническим оркестром.

Большую часть репертуара труппы составляли классические русские балеты, современный балетный репертуар танцевальной труппы С. П. Дягилева и классическое наследие европейского балета. Артисты демонстрировали качественное исполнение и тем самым способствовали распространению классического танца. Руководствуясь совершенно разными идеями, воплощая разные стили, они внесли масштабный вклад в развитие труппы, тем самым одновременно развивая традиции русского балета как в Шанхае в частности, так и в Китае в общем.

С тех пор в Шанхае регулярно показывались балетные постановки. Это был единственный пример длительной и беспрерывной работы русского театрального коллектива в Шанхае и знаковое событие для китайского 
балета. «2 февраля 1935 года артисты труппы “Русский балет в Шанхае” впервые выступили в театре “Лайсеум", где исполнили три фрагмента из балетов разных стилей - классического балета "Сильфида" в постановке А. Г. Недлер, современного балета "Маски города" в постановке Э. И. Элирова и балетного фрагмента "Половецкие пляски” из оперы “Князь Игорь” в редакции Н. М. Сокольского. Спектакли были чрезвычайно эффектными и имели огромный успех, а зрители, полностью заполнившие зал, не хотели покидать его в течение длительного времени» [11, с. 413]. После этого успеха русская классическая танцевальная труппа претерпела много трудностей на своем творческом пути, но, справляясь с ними, становилась только сильнее и профессиональнее. Один успешный сезон следовал за другим, способствуя росту репутации Н. М. Сокольского, а публика все больше восхищалась его работой.

В течение десяти лет - с 1934 по 1943 годы - почти всем другим балетным труппам требовалась поддержка (в виде крупных сумм государственных субсидий или частных пожертвований), дающая возможность поддерживать непрерывную работу творческого коллектива. Но труппа «Русский балет в Шанхае» развивалась и росла без какой-либо помощи со стороны шанхайских властей, полагаясь исключительно на видение и организаторские способности своего руководства, его координацию в театральном мире и умение действовать, опираясь на энтузиазм артистов труппы. «Русский балет в Шанхае» этого периода с его танцовщиками, стремлением приобщить публику к новой эстетике, сохраняя при этом классическое наследие, несомненно, заслуживает памяти о себе.

Даже после 1946 года, когда экономическая ситуация в Шанхае ухудшилась и русские певцы и танцовщики уже с трудом сводили концы с концами, они продолжали выступать в театре «Лайсеум» с той же преданностью к любимому искусству. Однако политические перемены со всей неизбежностью сказались на развитии искусства. В 1945 году закончилась Вторая мировая война, и обстановка во всем мире начала меняться. По призыву правительства СССР многие русские, остававшиеся за рубежом, начали возвращаться на родину, и некоторые артисты и солисты из труппы Сокольского в 1947 году тоже вернулись в СССР.

Принципы преподавания и школа балета Сокольского в Китае

В конце 1940-х годов Н. М. Сокольский ещё оставался в Шанхае, но с уходом лучших артистов работать стало сложно, положение труппы с каждым днем ухудшалось, и восстановить ее прежнее положение стало невозможным.

Но влияние личности Сокольского на китайский балет не ограничилось созданием труппы. Следует отметить еще одну из важнейших заслуг Сокольского перед китайским балетным театром: в 1934 году он сам стал первым преподавателем собственной балетной школы. Занятия в ней велись систематически, на высоком профессиональном уровне и проходили пять дней в неделю. Из них три дня отводились обучению классическому танцу, один день - народно-сценическому танцу, еще один - урокам гимнастики. «Кроме того, Н. Сокольский также приглашал всемирно известных танцовщиков, таких как европейский мастер танцев Юстус-Кейл Паскаль (Justus Keil Pasqual. - Ч. T.), на краткосрочные курсы обучения в школе, а также готовил с учениками сольные концерты для родителей в театре “Лайсеум” в летние каникулы» [15, с. 52-53]. Сольные номера в концертах были интересны и красочны, многие из них были поставлены Сокольским в соответствии с возрастом, способностями и уровнем подготовки каждого ребенка в классе.

Многие ученики Сокольского, прошедшие обучение в его школе, стали известными китайскими танцовщиками, педагогами, хореографами, авторами научных книг и статей, посвященных искусству танца. Среди них наиболее известна Ху Жунжун, позже опубликовавшая книгу воспоминаний. «Она исполняла танцевальные спектакли, поставленные Сокольским, такие как “Лебединое озеро”, “Спящая красавица" и “Щелкунчик”. В мае 1945 года она также провела свой собственный вечер и исполнила Рas de deux из балета “Дон Кихот"» [Там же, с. 56-59] (Илл. 3).

С созданием в 1949 году Китайской Народной Республики политический и культурный центр переместился в Пекин. Это вызвало распад труппы «Русский балет в Шанхае». Ученик Н. М. Сокольского Е Нин (в то время преподаватель Центральной академии драмы) предложил ему и его жене Е. П. Барановой работу в Центральной академии драмы в качестве преподавателей первого в КНР Театрального педагогического колледжа (Илл. 4).

«В июле 1949 года по результатам обсуждения во время первой Национальной конференции деятелей культуры и искусства в Пекине было отмечено, что уровень образования и выступлений в танцах необходимо срочно улучшить, а условия создания профессиональных танцевальных колледжей являются не вполне приемлемыми. 15 марта 1951 года под непосредственным руководством Министерства культуры и Центральной академии драмы был официально создан “Учебный курс по танцевальному движению” (образовательная программа, по которой преподавали танец в Театральном педагогическом колледже. - Ч. T.). Руководителем курса был назначен У Сяобан, а 68 учеников постигали там 12 танцевальных дисциплин (в том числе классический и народно-сценический танец, китайские народные и китайские классические танцы). Ученики занимались также изучением записи танца по системе Р. Лабана, теорией танца, практическими и музыкальными дисциплинами, изучали предмет "Искусство хореографа” и сценическое искусство. Много часов отводилось занятиям по литературе и повышению политической грамотности. Учителями балета и зарубежного народного танца были Е Нин, Ло Чжан, Чэн Дайхуэй, Сокольский и Баранова. Изучая основные приемы классического танца, а также репетируя танцы русские, украинские, польские, чешские, испанские и другие, студенты расширяли свой кругозор и осваивали разные танцевальные стили» [14, с. 14]. 


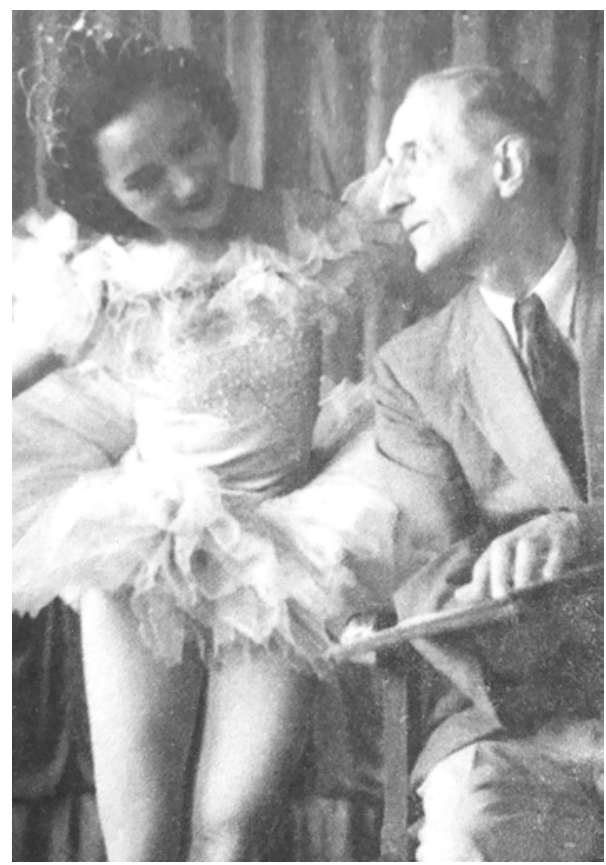

Иллюстрация 3. Н. М. Сокольский и Ху Жунжун. Шанхай (илл. из книги «Чудесный цветок китайского балета - Ху Жунжун») [15]

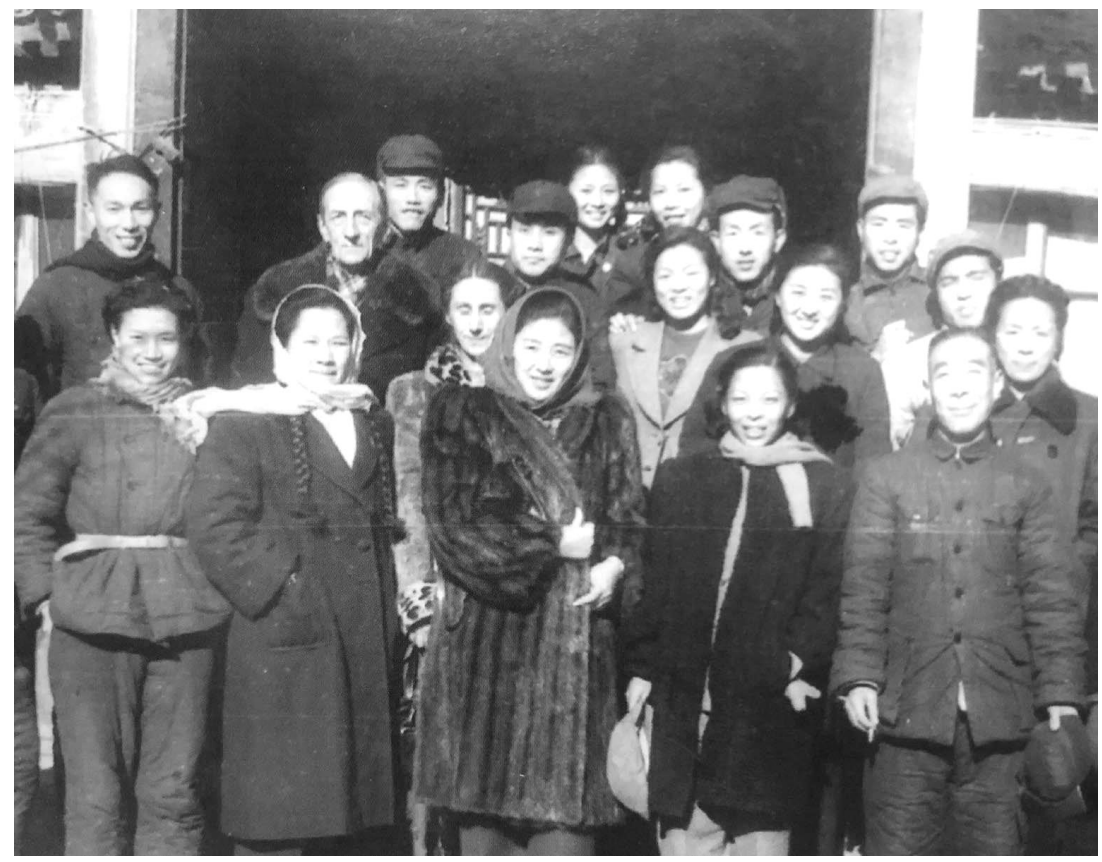

Иллюстрация 4. Н. М. Сокольский в окружении коллег из Министерства культуры и Центральной академии драмьл. Пекин (илл. из книги «Краеугольный камень таниа в новом Китае») [12]

Манера преподавания Сокольским предмета «Учебный курс по танцевальному движению» была понятна студентам, что приносило свои плоды. Его знания и профессионализм, дотошное отношение к работе, а также его доброта и энтузиазм по отношению к ученикам запомнились ими навсегда, что подтверждают их многочисленные воспоминания.

Ли Чэнсян, который студентом прошел этот «Учебный курс...», в своей статье «Мечты начинаются отсюда» отмечал, что его педагог Сокольский был «знающим и добрым учителем» [12, с. 142]. В статье «Обзор истории» Лан Тянь писал: «Два русских учителя (Сокольский и Баранова), которые преподавали методику классического танца, были так же хороши и на практических занятиях. Студенты не только отрабатывали технику, но и формировали координацию движений» [Там же, с. 120]. Эта выработанная методика преподавания оказывала положительное влияние и на другие танцевальные дисциплины.

Зи Хуаю в статье «Урок счастливой молодежи» так вспоминала об одном из занятий: «Когда Сокольский и Баранова репетировали фрагмент из балета “Спящая красавица” для кордебалета, они позволили учителю танца Ян Фань и мне станцевать вариацию принцессы Авроры. <..> Этот танец очень сложный, мы репетировали 
один, два, десятки раз, а балетные туфли были мокрыми из-за стертых в кровь пальцев ног. Но эта вариация была исполнена и дала мне очень хорошую практику» [Там же, с. 411].

Тан Чжэнь в статье «Незабываемая танцевальная труппа. Незабываемые старые друзья» писала так: «В танцевальной труппе меня обучали два профессора - Баранова и Сокольский, прекрасно владеющие всем арсеналом движений классического танца, в том числе умением танцевать “на пальцах” в специальных туфлях классической танцовщицы - пуантах. Это умение еще больше расширило мои знания в области классического танца» [Там же, с. 275].

В статье «Танцевальная труппа заложила прочную основу моей танцевальной карьеры» Юнь Инши отмечал: «Два русских артиста балета научили нас систематической и профессиональной работе на уроках классического танца. Метод преподавания учителя классического танца на уроке - это строгость и требовательность. Например: однажды на пируэтах (вращениях) я не смог удержать центр тяжести и внезапно упал на пол, поднялся с пола и на максимальной скорости продолжил вращаться. В другом конце зала г-жа Баранова, женщина с красивыми голубыми глазами, повторяла: "Пируэт, пируэт, пируэт. Сделаете меньше кругов, и вам придется бежать назад и повторять все снова”. Студенты выросли и повзрослели за эти несколько лет упорных практических занятий и репетиций» [Там же, с. 401].

Именно благодаря неустанным усилиям таких подвижников, как Сокольский, из «Класса подготовки танцевальных кадров» вышло большое количество профессиональных китайских педагогов танца, в том числе известные учителя, хореографы, теоретики и деятели культуры и искусства Китая в области танца: У Фукан (профессор, директор секции преподавания и исследований танцев и академии народного танца Пекинской академии танца), Чжу Пин (старший преподаватель, вице-президент Шанхайской школы танца), Ло Сюнян (исследователь, консультант академического комитета Пекинской академии танца), Гао Дакунь (профессор, директор департамента китайского классического танца Пекинской академии танца), Сунь Ин (профессор, заместитель начальника секции преподавания и исследований китайского классического танца Пекинской академии танца, директор библиотеки Пекинской академии танца), У Юнь (танцовщик-премьер, заместитель председателя Ассоциации танцовщиков Внутренней Монголии), У Юйцинь (преподаватель), Тянь Цзин (хореограф), Ли Чэн (заместитель руководителя вокально-танцевальной труппы Народного художественного театра Тяньцзиня, вице-президент Ассоциации танцоров Тяньцзиня), Лю Чжицзюнь (старший преподаватель, заместитель председателя Ассоциации танцоров Шаньдуна), Лю Эньбо (исследователь, преподаватель), Лян Шуянь (хореограф, вице-председатель Ассоциации танцоров Сианя), Ючи Цзяньмин (хореограф, заместитель председателя Ассоциации танцовщиков Цзянсу), Ман Хэнъюань (заместитель председателя Ассоциации танцовщиков Шаньдун), Ван Юйсинь (председатель Ассоциации танцовщиков Цинхай), Цзин Мэй (хореограф, вице-председатель Ассоциации танцовщиков Шэньси), Цзоу Цзянь (хореограф, заместитель председателя Ассоциации танцовщиков Ляонина), Чжан Пэйцан (доцент, преподаватель Пекинской академии танца), Син Чживэнь (художественный руководитель первой сцены, заместитель председателя Китайской ассоциации танцоров, президент журнала «Танец») и многие другие.

Благодаря усилиям Сокольского в Китае впервые появилась практика профессионального обучения классическому танцу, что заложило основу для создания системы китайского танцевального искусства. В то же время была укоренена строгая педагогическая методика русской балетной школы.

Таким образом, проведенный анализ влияния работы Н. М. Сокольским на ранний китайский балет позволяет сделать следующие выводы:

- во-первых, в начале XX века в Китае балетные спектакли и педагогическая деятельность русских эмигрантов сосредотачивались только в Харбине и нескольких крупных городах (прежде всего - в Шанхае). Сокольский сформировал балетные коллективы, которые показывали в Китае русские балеты, современные постановки труппы С. П. Дягилева и спектакли западноевропейского классического репертуара. В определенной степени деятельность русских эмигрантов и, разумеется, Сокольского изменила уровень эстетического восприятия шанхайской публики, ускорила распространение западной танцевальной культуры в Китае и усилила её влияние;

- во-вторых, еще в начале XX века Сокольский основал собственную балетную школу в Шанхае, привезя из Петербурга строгую, уже сложившуюся систему преподавания балета. В собственной работе Сокольский, главным образом, опирался на практические подходы Н. Г. Легата и Э. Чекетти. Китайские студенты, изучавшие балет в то время, были в основном любителями, но они совершенствовались и стали талантами, которые в дальнейшем продолжили развитие классического танцевального искусства в Китае. Среди них можно отметить таких, как Ху Жунжун, Пэн Сонг, Е Нин, Цюй Вэй, Дин Нин, Юань Шуйхай, Ван Кефен, Юань Чунь. Эти и многие другие танцовщики окажут в будущем значительное влияние как на китайские, так и на зарубежные балетные школы.

В Пекине Сокольский преподавал классический танец и историю балета в рамках «Учебного курса по танцевальному движению». Кроме того, он делился своим опытом с учениками Центральной академии драмыпервой высшей академии театрального образования в КНР, которая готовила основные кадры для ранней китайской танцевальной культуры. Сокольский способствовал накоплению опыта для развития китайского балета во второй половине XX века, заложил основу в развитие раннего балета в Шанхае, в Пекине и во всем Китае.

Интегрируя элементы китайского танца, Сокольский создал собственный жанр танцевального представления, тем самым обогатив балетную школу, названную его именем. 
1. Вечер памяти, посвященный хореографам Сокольским, прошел в Великих Луках [Электронный ресурс]. URL: https://m.pln24.ru/vln/culture/307323.html (дата обращения: 22.10.2019).

2. Жиганов В. Д. Русские в Шанхае. Шанхай: Слово, 1936. 330 с.

3. Жэнь Шуай. Китайская «образцовая революционная опера»: жанрово-стилевые особенности: дисс. ... к. иск. СПб., 2019. 240 c.

4. Русские в Китае. Исторический обзор: сборник / общ. ред. А. А. Хисамутдинова. Шанхай: Издательство Координационного совета соотечественников в Китае и Русского клуба в Шанхае, 2010. 572 с.

5. Сунь Лу. Китайская народная опера: к проблеме становления и развития жанра: автореф. дисс. ... к. иск. Ростов-наДону, 2016. 30 с.

6. Хисамутдинов А. А. Русский балет в Китае. Владивосток: Издательство Дальневосточного университета, 2015.80 с.

7. Хисамутдинов А. А. С любовью к искусству: русские артисты в Китае. Владивосток: Издательство Дальневосточного университета, 2017. 62 с.

8. Чжан Личжэнь. Современная китайская опера (история и перспективы развития): автореф. дисс. ... к. иск. СПб., 2010. 24 c.

9. 汪之成, 上海俄侨史, 上海: 上海三联书店, 1993. 832页 (Ван Чжичэн. История русской эмиграции в Шанхае. Шанхай, 1993. 832 с.).

10. 汪之成, 上海的俄国文化地图, 上海: 上海锦绣文章出版社, 2010. 151页 (Ван Чжичэн. Карта русской культуры в Шанхае. Шанхай, 2010. 151 с.).

11. 汪之成, 俄侨音乐家在上海 (1920s-1940s) 上海音乐学院出版社 上海 2007. 579页 (Ван Чжичэн. Музыканты русской эмиграции в Шанхае (1920-1940-е гг.). Шанхай, 2007. 579 с.).

12. 董锡玖、隆荫培, 新中国舞蹈的奠基石, 香港: 天马出版社, 2008. 790页 (Донг Сицзю, Лун Иньпэй. Краеугольный камень танца в новом Китае. Гонконг, 2008. 790 с.).

13. 刘青式, 中国舞蹈通史 (中华民国卷1912-1949), 上海: 上海音乐出版社, 2010. 548页 (Лю Циньи. История китайского танца (1912-1949). Шанхай, 2010. 532 с.).

14. 田静、李百成 新中国舞蹈艺术的摇篮, 北京: 中国文联出版社, 2005. 560 页 (Тянь Цзин, Ли Байчэн. Колыбель нового китайского танцевального искусства. Пекин, 2005. 560 с.).

15. 杨洁 芭坛奇苑舞中华，上海：上海锦绣文章出版社，2013. 209页 (Ян Цзе. Чудесный цветок китайского балета Ху Жунжун. Шанхай, 2013. 209 с.).

\title{
N. M. Sokolsky's Impact on the Early Chinese Ballet
}

\author{
Zhang Tianjiao \\ Russian Institute of Theatre Arts (GITIS), Moscow \\ Tianj.zhang@yandex.ru
}

The article discusses N. M. Sokolsky's impact on the early Chinese ballet. He created the ballet troupe "Russian Ballet in Shanghai" thereby contributing to the spread of classical dance throughout China. The paper also mentions a pleiad of the talented Chinese artists - N. M. Sokolsky's disciples - who made a great contribution to the development of the national dance culture. It is noted that Sokolsky's initiative changed aesthetic perception of Shanghai public, accelerated spread of the western dance culture in China and strengthened its impact on the professional community. Relying on memoirs of Sokolsky's disciples, the researcher examines principles of his pedagogical work in the Central Academy of Drama (the first higher theatrical education institution in China). Finally, the author draws conclusion about Sokolsky's impact on the early Chinese ballet.

Key words and phrases: ballet; China; N. M. Sokolsky; "Russian Ballet in Shanghai"; training course on dance movement; foreign influence on the Chinese ballet. 